\title{
Introduction
}

\section{Moving evidence-based crime prevention forward tying good theory and evaluation research together}

\author{
Security Journal (2011) 24, 195-197. doi:10.1057/sj.2011.9
}

In the late 1990s, major US retailers were installing retail crime prevention tools to help stem their billions of US dollars in merchandise losses. One particular retailer reportedly invested almost US\$200 million in an anti-theft system based on a simple year-to-year comparison of a specific high-loss item. Further, on the basis of our personal knowledge of the situation, the retail organization did not select the expensive countermeasure based on understanding the crime problem's opportunity structure, or how the selected crime prevention treatment's mechanism of action would work to reduce the likelihood of theft. Modern criminological literature provides crime prevention decision makers with many tools and options to analyze specific crime problems to more precisely design countermeasures, as well as an array of impact evaluation designs.

In the case of the retail company, a later randomized controlled trial (RCT) of the above mentioned crime prevention treatment did not find evidence of the intervention's efficacy, and unfortunately could not support its cost-effectiveness (Hayes and Blackwood, 2006). This unfortunate finding might well have been different had the organization carefully designed and deployed their crime prevention countermeasure. It is important to keep in mind evidence-based crime prevention was not well accepted at the time, and in fact was almost unheard of then.

Times have not changed the retail industry's crime prevention process completely, but the retailer in question is now helping lead the evidence-based loss prevention and asset protection charge these days. They, like so many others, are realizing life safety, serious financial losses, organizational reputation, and the need to effectively compete in the business world means crime and loss control should be more fact-based and follow environmental criminological theory to make a significant and profitable difference.

This special Security Journal issue is devoted to help further the goal of more efficacious and cost-effective crime prevention by describing recent theory-guided action research, and research suggestions, to help practitioners and scientists work together to reduce crime events by situationally altering real or perceived crime opportunity structures (Clarke and Eck, 2005; Eck and Madensen, 2009). Part of this evidence-based crime prevention process involves conducting qualitative research that helps scholars and field decision makers better understand priority problems and their situational dynamics in order to more precisely focus preventive interventions and their mechanisms of action.

In addition, part of the evidence-based crime prevention process means conducting contextual, rigorous evaluation research of current and emerging crime prevention programs and tools. The evidence-based process also means crime prevention treatments can not 
only be rigorously evaluated using RCTs or other comparison designs where life safety and serious financial risk is involved, but RCTs or similar methods should be combined with thorough context-mechanism-outcome $(\mathrm{C}-\mathrm{M}-\mathrm{O})$ descriptions in order to more accurately understand treatment effects, strengths and shortcomings for ongoing prevention mechanism improvement and impact enhancement. RCTs are certainly not the only or even always the best crime prevention evaluation design for many projects, but their internal validity and the effect size estimates they provide - especially when combined with a complete C-M-O and SARA (scanning, analysis, response, assessment) exercise - promise crime prevention practitioners best evidence for their high-stakes decisions (Sherman, 2003; Weisburd, 2010).

\section{This Issue}

This issue contains both original research, and lessons learned from recent research to provide further evidence-based crime prevention information to scholars and practitioners alike. The first paper by University of Leicester's Adrian Beck provides research on self-scan checkouts (SSCs), which has seen a significant amount of growth in the retail community. However, there is a lack of research regarding SSCs and retail theft. Crime prevention theory concludes that retailers should consider creating 'zones of control' for self-scan areas. Further, offenses may occur based on customer frustration with SSCs; theories of neutralization, situational prevention and cognitive dissonance can help explicate the increasingly multifaceted relationship between consumers and retail spaces.

Mike Scicchitano elucidates, in his paper, the role of RCTs in supporting retail loss prevention decision making. In addition, he highlights some of the limitations to the validity of results when implementing RCTs in the retail environment. His paper draws upon extensive knowledge in conducting RCTs for major US retailers that provided important information in order to guide decisions regarding the adoption of loss prevention solutions that could potentially save the retail community millions in reduced loss.

There has been a paucity of research regarding risk assessment before implementation of risk management measures. Tracy Johns looks at the intricate role of risk management models in the retail environment as they relate to asset protection. Even though nearly all retailers use risk assessment measures in order to attempt to eliminate or minimize theft and other crimes, there is a lack of knowledge regarding how many undergo systematic risk assessments of loss to guide their solutions. Dr Johns provides the findings of a survey of 22 large US retail companies regarding their loss prevention risk management method, including the types of risk data obtained, types of risk assessment and analyses administered, and how these data are implemented in management decisions.

The last paper by Read Hayes and Daniel Downs uses the situational crime prevention framework to shape and later evaluate three situational crime prevention measures in retail stores by first articulating their contextual mechanisms of action, then using an RCT to measure their impact on hot product loss and sales levels.

We sincerely hope the following papers provide some meaningful results and thought around using theory and best methods to realistically shape crime control and impact. 


\section{Acknowledgements}

We would like to acknowledge and thank Corrie Tallman for her expert editing, Bonnie Fisher and Heidi Scherer for their patient shepherding, the paper authors and reviewers, and David Williams for his diligent efforts in bringing this special edition together.

\section{References}

Clarke, R.V. and Eck, J.E. (2005) Crime Analysis for Problem Solvers. In 60 Small Steps, Office of Community Oriented Policing Services. Washington, DC: US Department of Justice.

Eck, J.E. and Madensen, T. (2009) Using signatures of opportunity structures to examine mechanisms in crime prevention evaluations. In: J. Knutsson and N. Tilley (eds.) Crime Prevention Studies, Volume 24: Evaluating Crime Reduction Initiatives. Monsey, NY: Criminal Justice Press.

Hayes, R. and Blackwood, R. (2006) Evaluating the effects of EAS on product sales and loss: Results of a largescale field experiment. Security Journal 19(4): 262-276.

Sherman, L.W. (2003) Misleading evidence and evidence-led policy: Making social science more experimental. Annals of the American Academy of Political and Social Science 589(1): 6-19.

Weisburd, D. (2010) Justifying the use of non-experimental methods and disqualifying the use of randomized controlled trials: Challenging folklore in evaluation research in crime and justice. Journal of Experimental Criminology 6(2): 209-227.

Read Hayes

Crime Prevention Research Team, University of Florida, Gainesville, Florida, USA. E-mail: rrhayes@ufl.edu

Daniel M. Downs

Loss Prevention Research Council, Gainesville, Florida, USA. E-mail: ddowns@lpresearch.org 